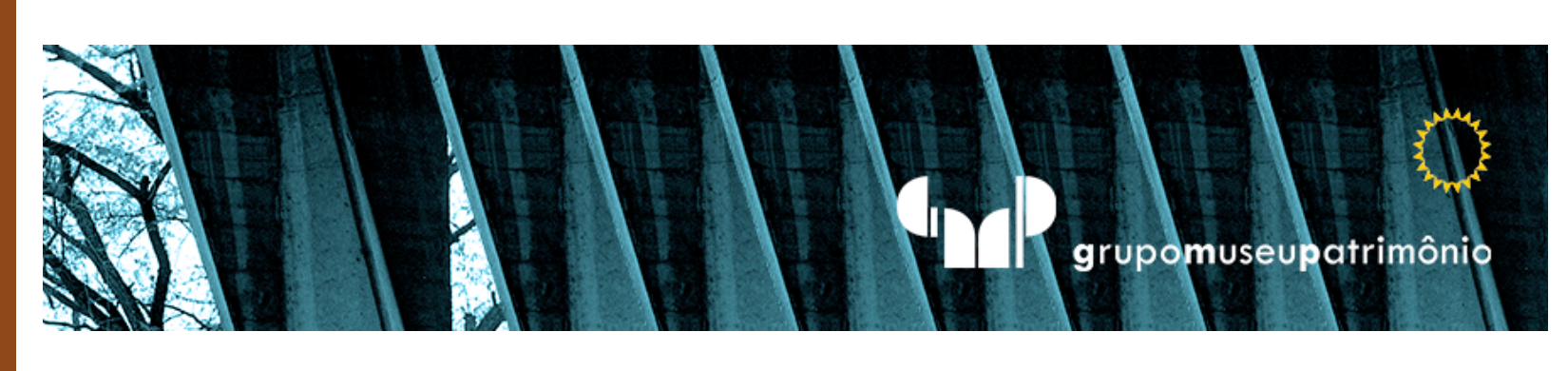

\title{
Representação feminina em tempos de exceção
}

Female image in time of exception

\section{Representación femenina en} tiempos de excepción

Amanda Saba Ruggiero FAU-USP, São Paulo, Brasil.amandaruggiero@gmail.com

Anna Maria A.K. Rahme FAU-USP, São Paulo, Brasil. annarahme@gmail.com 


\section{Resumo}

O artigo parte dos conceitos de tempo e representação - estudados por Roger Chartier, com análises sobre a importância das narrativas, enquanto discursos empregados na fixação da(s) memória(s) e a construção da historia cultural de um determinado grupo -, para associá-los às proposições curatoriais da exposição Mulheres Radicais: arte latino-americana 1960-1985, uma mostra de criações artísticas femininas resistentes às ditaduras militares que oprimiram a América Latina durante a segunda metade do século XX.

Palavras-Chave: mulheres.arte.história.representação.exposição.

\section{Resumen}

El artículo parte de los conceptos de tiempo y representación - estudiados por Roger Chartier, con análisis sobre la importancia de las narrativas, como

discursos empleados en la fijación de la(s) memoria(s) y la construcción de la historia cultural de un determinado grupo-, para asociarla a las proposiciones curatoriales de la exposición Mujeres Radicales: arte latinoamericano 19601985, una muestra de creaciones artísticas femeninas resistentes a las dictaduras militares que oprimieron a América Latina durante la segunda mitad del siglo $X X$

Palavras-Clave: mujeres. arte. história. representación. exposición

\section{Abstract}

The article is based on the concepts of time and representation - studied by Roger Chartier, on narratives, as discourses for the permanece of the memory (ies) and the construction of the cultural history of a certain group - it aims to (ies) and the constions to Latin American Art 1960-1985, an exhibition of feminine artistic creations Latin American Art 1960-1985, an exhibition of feminine artistic creations
resistant to military dictatorships that oppressed Latin America during the resistant to military dictatorships that
second half of the twentieth century.

Keywords: women.art.history.representation.exhibition

\section{APRESENTAÇÃo}

bjeto da reflexão proposta, a exibição Mulheres Radicais: arte latinoamericana 1960-1985 esteve em cartaz na Pinacoteca do Estado de São Paulo de agosto a novembro de 2018. Para análise dos argumentos, temas e obras, propostos pela curadoria ${ }^{2}$ - Cecilia Fajardo-Hill, Andrea Giunta e Valéria Piccoli -, elegeu-se como referência teórica as afirmativas anunciadas por Roger Chartier, relativas aos conceitos de história, narrativa, representação e ficção a fim de compreender o conjunto dos trabalhos, friç̧ões, sentidos e a relação com o contexto social e político do atual Brasil, único pais da América Latina a receber a exposição.

Note-se a relevância do evento na ocasião em que mulheres saíram às ruas para manifestar contra o preconceito, o racismo e a desigualdade de gênero, ${ }^{2}$ Sob o patrocínio da Getty Foundation, a exposição itinerante teve iníicio no HammerMuseum,
Los Angeles, e conta com a curadoria de Cecilia Fajardo-Hill (historiadora da arte e curadora),
Andrea Giunta (pesquisadora e curadora) e, excepcionalmente no Brasil, Valéria Piccoli (curadora-chefe da Pinacoteca). 
num cenário marcado por ameaças às conquistas democráticas ${ }^{3}$. Trazer à tona peças realizadas, em sua maioria, há mais de quarenta anos, sinaliza apreço e reconhecimento pela luta feminina que se anunciou nos anos 60 e persiste atual e necessária. Ademais, o efeito do conjunto recebeu ainda mais camadas de significados carregados das vibrações e debates contemporâneos que permeiam a dinâmica social e política universal da atualidade.

Em ações como estas, a memória (coletiva ou individual) constitui parâmetro fundamental para a construção de uma dada história cultural. Quando associadas à ideia de "presentificação do passado" defendida por Roger Chartier (1988), ao trazer a público, perpetuam e vinculam tais demandas ao contemporâneo. A mostra é pois a celebração necessária para a escritura de parte da história que não deve ser esquecida jamais. As obras artísticas, essas representações, constituem as práticas necessárias à sustentação dos discursos femininos entre 1960 e 1985, assim como se atualizam no contexto da época presente.

Este "[...] sustentar um discurso histórico como representação e explicação adequadas da realidade $[\ldots]$ " reitera o pensamento de Chartier sobre a "[...] emancipação da história com respeito à memória e com respeito à fábula, também verossímil [...]" (2010, p.24-31). E, ainda, como o autor defende, promove os fatores enumerados por Paul Ricoeur- o testemunho documental, a representação, os vestígios e sua (suposta) fidelidade histórica - na obra $A$ memória, a história, o esquecimento (2000).

Porque o valor da operação historiográfica - a representação - que funda a microhistória, se fortalece quando associada aos acervos e resquícios dos acontecimentos. São filmes, músicas, diários, artes plásticas que, desde o fim dos regimes de exceção, se juntam aos milhares de registros de época - testemunho

${ }^{3}$ Diversos jornais e revistas noticiaram a manifestação liderada por mulheres que ocorreu em diversas cidades do território nacional, ver: https:/ /www.bbc.com/portuguese/brasil-45700013, https://folha.com/sxhe76ma, documental - da polícia política, fotos, depoimentos gravados, bem como a fidelidade histórica dos vestígios, os locais e os instrumentos de aprisionamento e tortura, cemitérios clandestinos, desaparecimento de indivíduos.

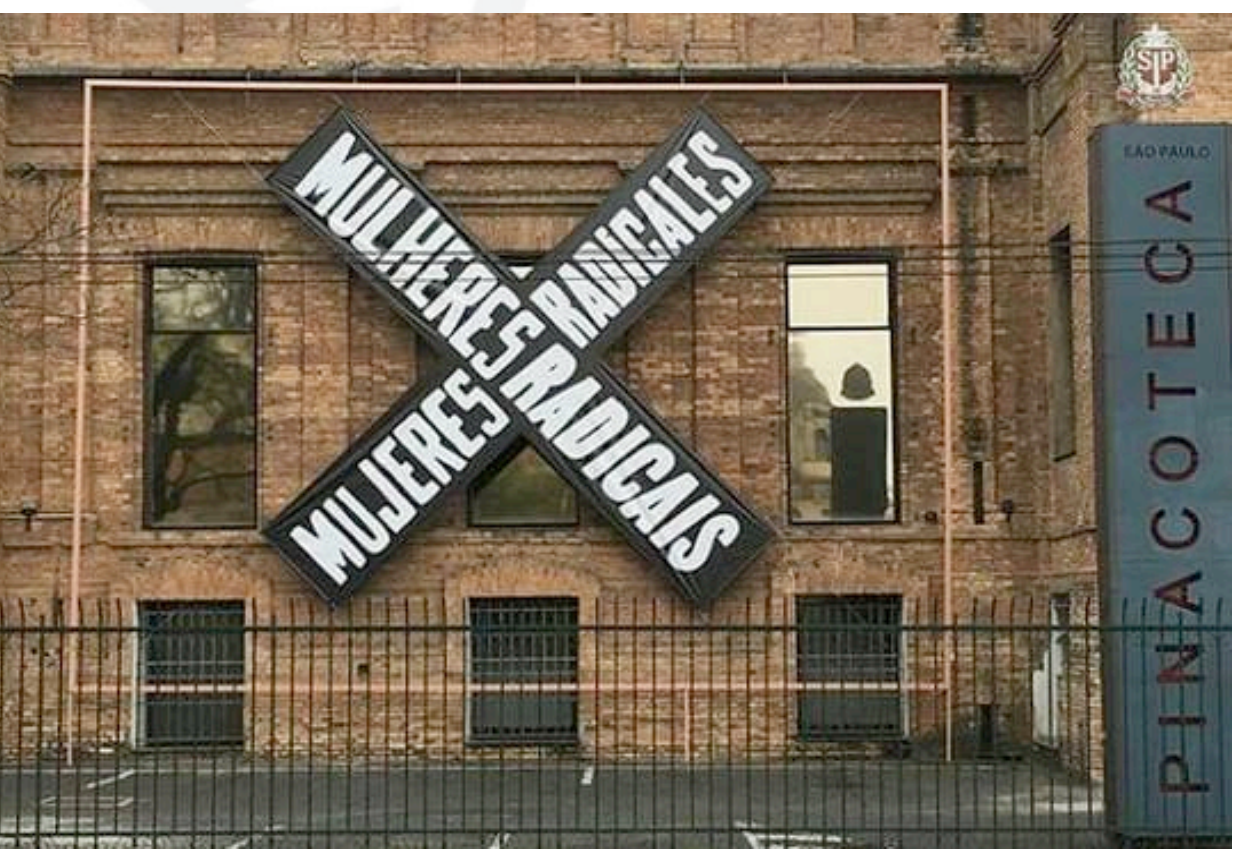

Figura 1. Logo de apresentação da exposição Mulheres radicais, na Pinacoteca do Estado de São Paulo, 2018, criado pela Agência FNascaSaachi\&Saachi. Fonte: Fotografia publicada no site da Pinacoteca, para divulgação do evento.

Neste contexto, as peças selecionadas para compor Mulheres radicais numa variada gama de representações, seja pelos temas ou pelos suportes, contribuem para o entendimento do recorte temporal, um período de acirramento da repressão e torturas pelas forças ditatoriais latino-americanas do século $X X^{4}$. Tal recorte, aplicado à pesquisa das curadoras Cecilia FajardoHill e Andrea Giunta, abrange fatos cuja duração total vai de meados dos anos 1950 até 1990, calando vozes e mutilando corpos. Não por acaso sons e

${ }^{4}$ Argentina (1976-83), Bolívia (1971-85), Brasil (1964-85), Chile (1973-90), Equador (1972-79), Paraguai (1954-89), Peru (1968-80), Uruguai (1973-84). 
corpos são os protagonistas da exposição ${ }^{5}$. Resultam da expressão artística, múltipla e intimamente conectada, de mulheres perseguidas social e politicamente, mas que não se permitiram calar diante do poder patriarcal norte americano e sua ingerência nos assuntos da América Central e do Sul.

O corpo feminino centraliza tematicamente a exposição devido à mudança de perspectiva que as artistas trouxeram para a história da arte. Este corpo feminino, antes objeto da representação - frequentemente nu e quase sempre criado por um homem - também produz arte e conduz a uma reflexão sobre si mesmo. A pesquisa, envolvendo o período de 1960 a 1985, contribui extraordinariamente para a mudança radical dos ideais anteriores, reunindo uma iconografia do corpo na arte que permite ver modificado um objeto em sujeito. Sujeito aqui organizado em torno dos temas: Autorretrato; Paisagem do corpo; Performance do corpo; Mapeando o corpo; Resistência e medo; 0 poder das palavras; Feminismos; Lugares sociais; Erótico.

A proposta é justificada nas vozes das curadoras, tanto pelos traços em comum "[...] as vidas e as obras dessas artistas estão imbricadas com as experiências da ditadura, do aprisionamento, do exílio, tortura, violência, censura e repressão, mas também com a emergência de uma nova sensibilidade [...]" (Fajardo-Hill, 2018), quanto pelo que as individualiza, na exploração dos tópicos poético e político "[...] em autorretratos, na relação entre corpo e paisagem, no mapeamento do corpo e suas inscrições sociais, nas referências ao erotismo, ao poder das palavras e ao corpo performático, a resistência à dominação; feminismos e lugares sociais [...]" (Giunta, 2018).

${ }^{5}$ A exposição na capital paulista encerra a itinerância do evento e conta com obras de 120 artistas provenientes de quinze países e reunindo mais de 280 trabalhos em fotografia, vídeo, pintura e outros suportes.

\section{CONTEXTUALIZAÇÃO: RECORTE HISTÓRICO}

As representaç̃̃es não são simples imagens, verdadeiras ou falsas, de uma realidade que Ihes seria externa; elas possuem uma energia própria que leva a crer que o mundo ou o passado é, efetivamente, o que dizem que é.

Michel Foucault

A tarefa e a responsabilidade do historiador, para Chartier, ainda é a leitura das diferentes temporalidades, "que fazem com que o presente seja o que é, herança e ruptura, invenção e inércia ao mesmo tempo" (2010, p.68). Do mesmo modo, o passado nunca é um objeto que já está ali, mas que será produzido pelo historiador por meio de práticas - recorte e processamento das fontes, mobilização de técnicas de análise específicas, construção de hipótese, procedimentos de verificação -, chamadas "operações". Já, "regras" e "controles" a inscrevem em um regime de saber compartilhado, definido por critérios de prova dotados de uma validade universal (2010, p.11-17).

Associando conhecimento e relato, prova e retórica, saber crítico e narração, Roger Chartier explica a cientificidade da história pelos saberes de Michel de Certeau e Carlo Ginzburg. Neste sentido, as obras presentes na exposição podem ser analisadas como relatos e discursos, que somados a outros documentos e fontes, testemunham contextos históricos em que figura feminina avança em apresentar, expor e denunciar atos de violência, repressão, discriminação por meio do corpo físico, social e político.

O "objeto fundamental de uma história que se propõe a reconhecer a maneira como os atores sociais dão sentido a suas práticas e seus enunciados" (p.49) é constituído pela tensão entre indivíduos e comunidades, com suas capacidades inventivas, ao lado das restrições e convenções limitadoras. Uma tensão que por vezes leva décadas para romper as amarras articuladas pelo poder instituído, apagando, mesmo que temporariamente, a memória dos fatos e sua consequente denúncia. Mais do que relembrar a história da repressão nos países latino-americanos, a exposição dá voz às sensibilidades e poeticamente 
transborda em ações políticas. As peças da mostra são parte da história das representações - textos e imagens como categorias mentais dadas a ler, escutar ou ver - e se vinculam à cultura escrita para fundar as matrizes das classificações e dos julgamentos.

Além da "[...] importância de um conceito como representação, que veio a designar, praticamente por si mesmo, a nova história cultural [...]", Chartier desafia a "pensar a articulação entre os discursos e as práticas" propondo o estudo da língua como sistema de signos, com significados múltiplos e instáveis, como também sobre o fato da realidade não ser “[...] uma referência objetiva externa ao discurso, mas é sempre construída pela linguagem [...]". Conclui, assim, que toda prática "[...] se situa, necessariamente, na ordem do discurso" (p.51-2)

Se por um lado, apresentar Mulheres radicais no Brasil, país afetado pela repressão por mais de vinte anos, é um fato impactante, por outro, juntar conjunto de peças marcadas pela intensidade dos discursos, abre a oportunidade de nos comunicarmos com os outros países envolvidos em situações análogas, no mesmo momento histórico, e avaliar as similaridades e distinções entre elas. Pois, enquanto "[...] os indivíduos e os grupos se percebem e percebem os demais", transmitem "as diferentes modalidades de exibição da identidade social ou da política tal como as fazem ver e crer os signos, as condutas e os ritos [...]" (p.51-2). Uma consciência de pertencimento, mas também a estabilidade e a continuidade de uma dada cultura.

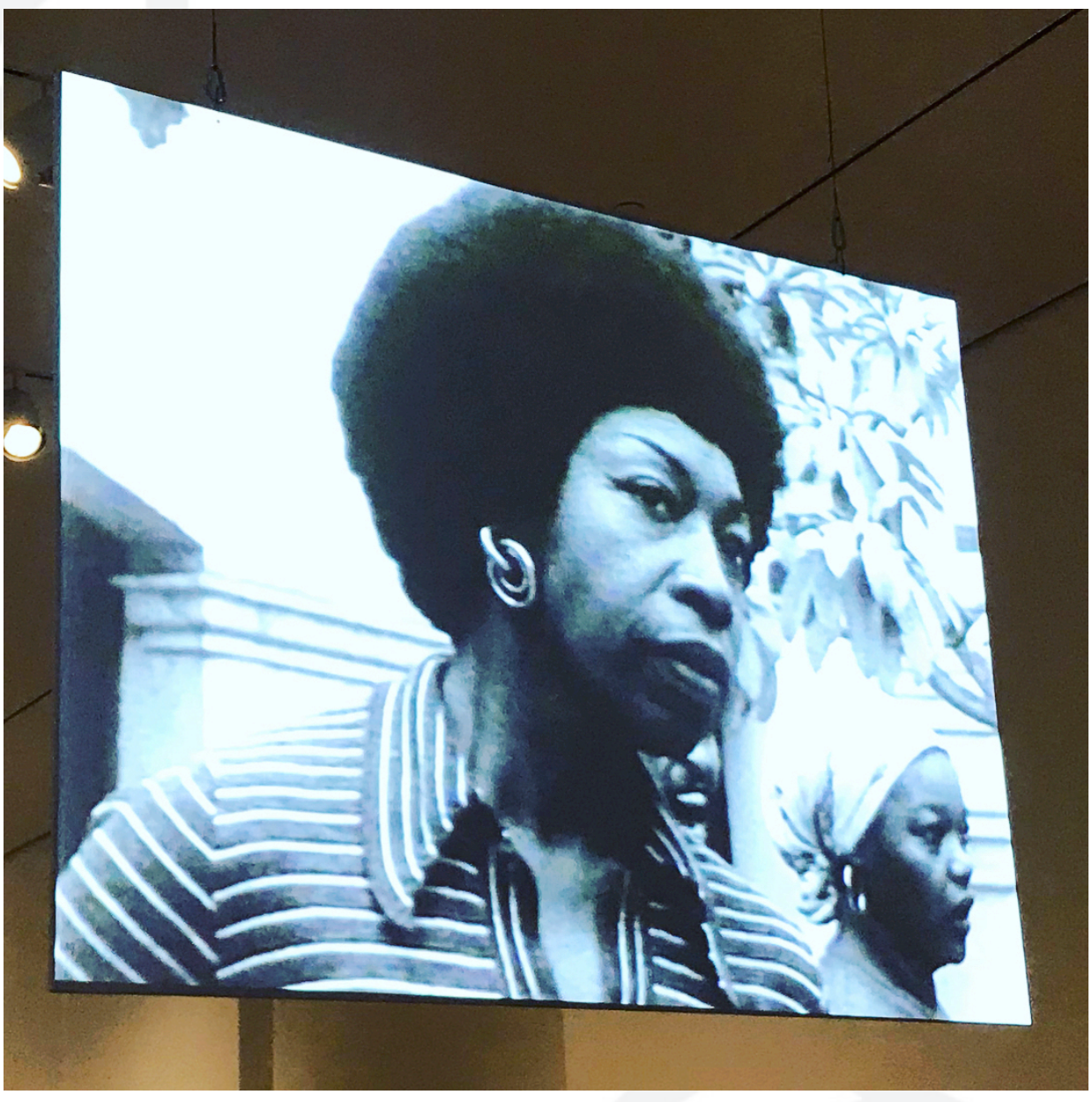

Fig. 2 - Foto do vídeo de Victoria Eugenia da Cruz Me Gritaron Negra. Fonte: Fotografia da exposição feita pelas autoras.

Exemplarmente, logo à entrada da exposição, um poema musicado da artista Victoria Eugenia da Cruz Me Gritaron Negra ${ }^{6}$, delata em vídeo a discriminação pela diferença, em que a palavra "negra" dirigida a uma criança resultou na rejeição pelo próprio corpo, a negação de seus cabelos, sua pele e características pessoais, até o momento no qual já mulher, diminuída cada vez mais por estas diferenças, é derrubada pelo ecoar das vozes a repetir Negra. Mas ela se levanta, olha para si, reconhece seu valor e compreende a força de

O $\mathrm{O}$ video completo com a letra do poema está disponivel em htps://www-youtube.com/watch?v=49-wQtOj7il 
ser uma mulher negra, em luta afirma sua identidade, também expressa pela gestualidade das demais pessoas que repetem em coro 'Negra, Negra, Negra'.

O tom das vozes, somado ao batuque de fundo, reforçam a tensão e a violência das palavras, denunciam o preconceito que ainda recai sobre a população negra. O discurso neste caso endossa e reafirma os relatos históricos da escravidão e discriminação étnica, ainda presente nos dias atuais. O vídeo revela um dos trabalhos mais fortes e impactantes da exposição ${ }^{7}$, mas teve sua apresentação na mostra Histórias Afro-Atlânticas (2018), tanto no MASP quanto no Instituto Tomie Ohtake, reduzida a dimensões similares às das obras expostas, pela reprodução em um monitor de 17 " preso na parede.

\section{CLASSIFICAÇÃO: NARRATIVAS DIVERSIFICADAS}

Autorretrato / Paisagem do corpo / Performance do corpo / Mapeando o corpo / Resistência e medo / O poder das palavras / Feminismos / Lugares sociais / Erótico.

Sob qual desses sub-temas poderíamos classificar a peça artística acima mencionada? E, ainda, seria ela poesia, performance, vídeo-arte? Talvez, ela caiba numa destas rotulações caso isolemos cada uma das expressões ali presentes, porém, nenhuma delas se adequa ao conjunto. E se considerarmos o aspecto de ativismo de gênero ou étnico? E se levarmos em conta a impostação das vozes e o movimento dos corpos? Enquanto as indagações são subjetivas, as respostas ficam por conta da recepção ${ }^{8}$ da obra de arte. Por

O poema Me Gritaron Negra é de autoria de Victoria Eugenia Santa Cruz, 1922-2014 (Lima, Peru), compositora, coreógrafa e desenhista, com destaque na arte afroperuano e no combate ao racismo.

Recep̧̧ão como a interação de uma obra de arte com o público, considerando os aspectos individuais e historicos, conforme proposta de Hans Robert Jauss (1994) para a teoria esteticorecepcional. Enquanto as referências adquiridas pessoalmente resultam numa fruição do objeto artistico que amplia o horizonte de expectativas contribuindo para novas analises e avaliaçoes, conhecimento historico fornece os elementos interpretativos com o efeito advindo
significados a ele atribuídos. outro lado, quanto ao fazer artístico, a evidência mais contundente é de um ato de resistência.

Embora o vocábulo tenha sido usado pela curadoria associado ao medo, talvez ele devesse designar o mote de cada um e todos os registros expostos. A designação também se ajusta à ação das organizadoras ao mostrar esse grupo de Mulheres radicais, caracterizando a obstinação por múltiplos vieses e, assim, multiplicando possibilidades de leituras, interpretações e vivências. E ao examinarmos o triplo significado para o conceito de exposição - "[...] tanto o resultado da ação de expor, quanto o conjunto daquilo que é exposto e o lugar onde se expõe ${ }^{\prime \prime}$ - devemos nos ater, além da recepção, ao fator da seleção apresentada, mas também, à escolha do local e ao modo de expor.

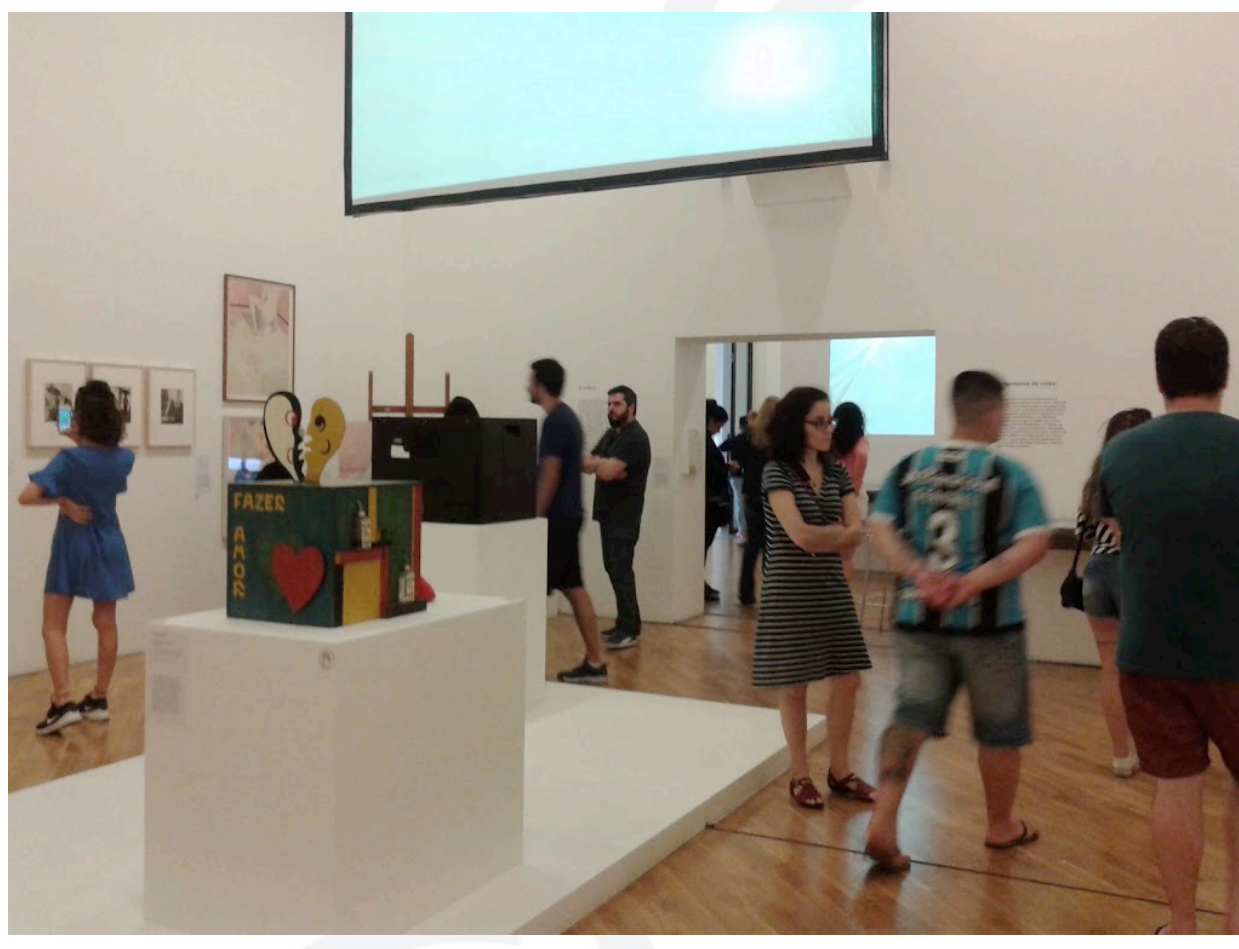

Fig. 3. Foto das salas da Pinacoteca durante a visitação. Fonte: Anna Maria Rahme "Definição para o termo "exposição" em "Conceitos-chave de museologia" (Desvallées e Mairesse, 2013, p.42). 


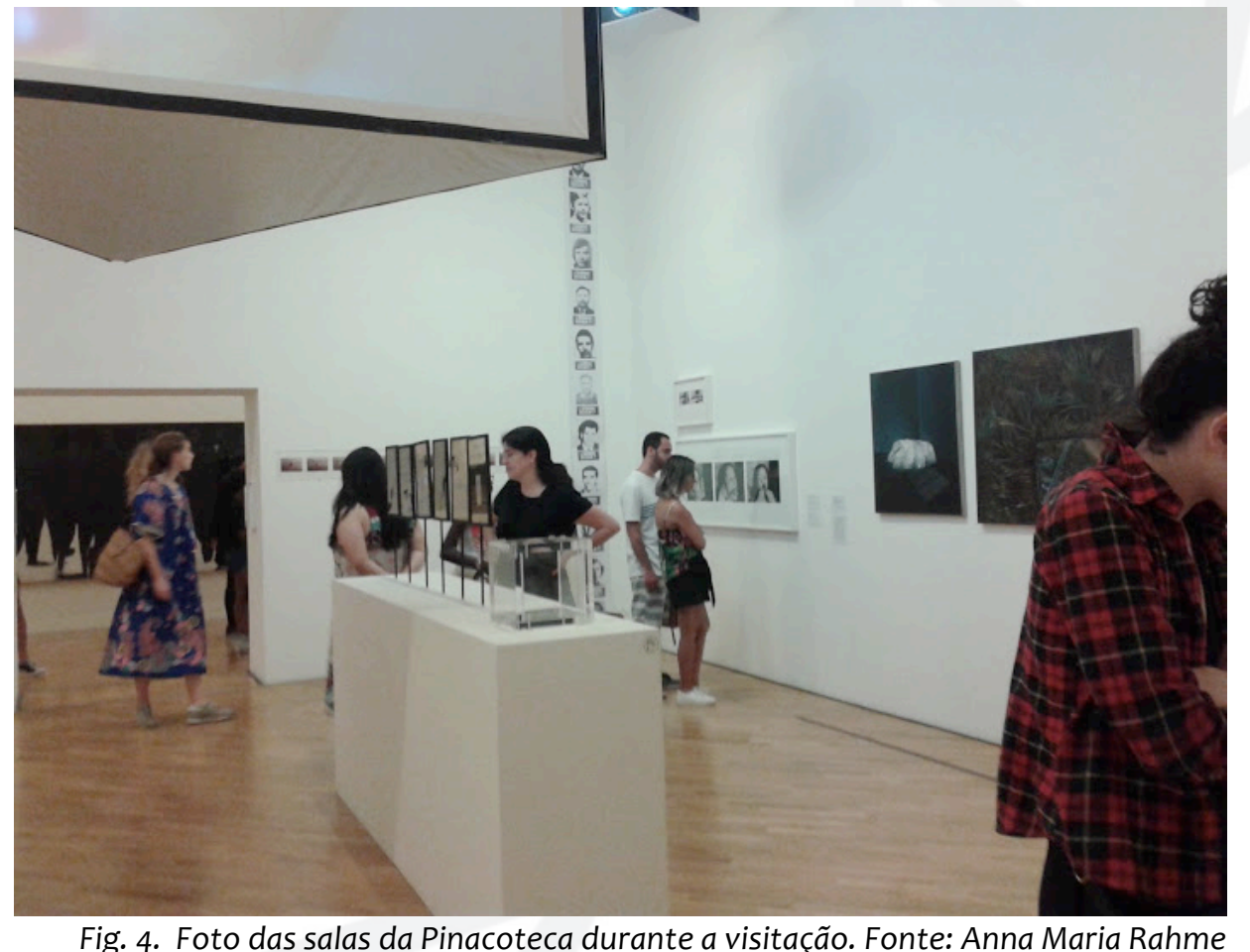

Fig. 4. Foto das salas da Pinacoteca durante a visitação. Fonte: Anna Maria Rahme

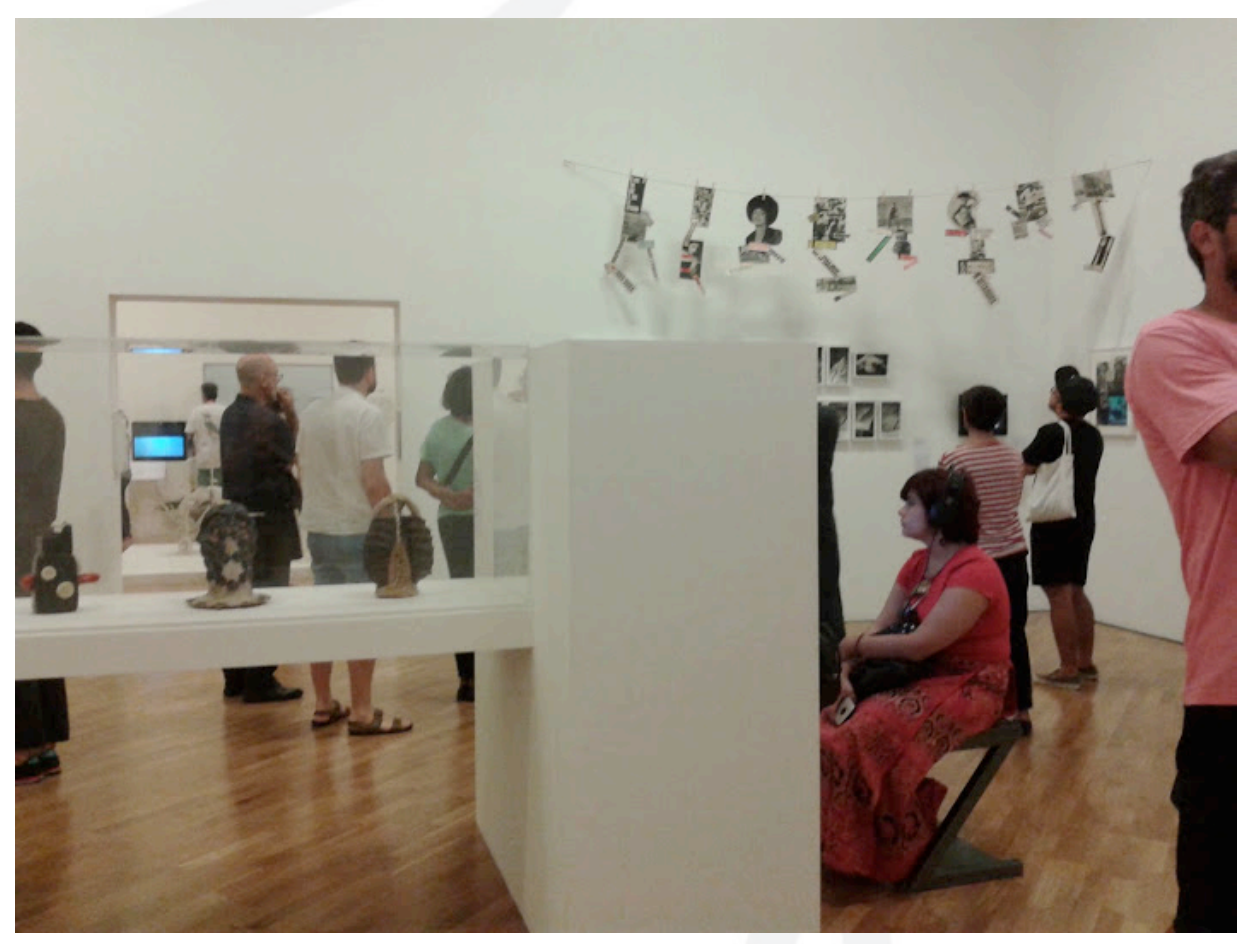

Fig. 5: Foto das salas da Pinacoteca durante a visitação. Fonte: Anna Maria Rahme
As análises dessas condiç̃oes tiveram origem nas reiteradas visitas à Pinacoteca do Estado, durante os dias da mostra ${ }^{10}$, colocando-nos em contato com um público de perfil bastante diversificado, entre feminino e masculino de diferentes idades e etnias, poder aquisitivo e opção de gênero. Em geral, reagindo entre a surpresa e a admiração, ao se depararem com o acúmulo de desenhos, vídeos, pinturas, fotos, montagens dispostos de modo quase caótico, pois, embora cada sala do museu estivesse destinada a um sub-tema, uma generosa abertura entre elas deixava ver e ouvir o exposto no espaço subsequente. Utilizou-se, na ocasião, museografia nada tradicional ${ }^{11}$, mesclando suportes, cores, movimentos e origens distintas em fotografias, pinturas, vídeo e objeto como em Paisagem do corpo, proposta para a primeira sala do roteiro sugerido.

Suspenso no centro da sala $O$ ovo, um imenso cubo em acrílico, cujas faces recebem a projeção de uma performance da autora Lygia Pape, toma conta do espaço, impedindo que as outras obras sejam fruídas. No vídeo, o corpo feminino, sujeito ativo e não em imagem idealizada, em plena ação numa praia se funde à natureza no ritual, no processo e no significado mesmo da sequência de movimentos que desenham um processo de transformação. Numa das paredes, cenas em movimento revelam a Passagem, de Celeide Tostes, na qual a fertilidade e o feminino são referências mais próximas da natureza, do despertar para um renascimento, um processo cíclico de vida e renovação.

${ }^{10}$ As observaç̧ões das autoras resultaram a partir de quatro visitas à exposição, distribuídas entre a primeira e a ultima semana do evento.

${ }^{11}$ Entenda-se por "museografia tradicional” aquela que organiza os espaços de forma linear, se preocupa com unar apresentaçăo cronologica das peças, apresenta as peças planas posicionadas ou estantes horizontais. Grande parte destas características esteve presente na citada exposiç̃ão Histórias Afro-Atlânticas, exibida simultaneamente pelo Museu de Arte de São Paulo Assis Chateubriand/MASP e o Instituto Tomie Ohtake, de 29/06 a 21/10 de 2018. 


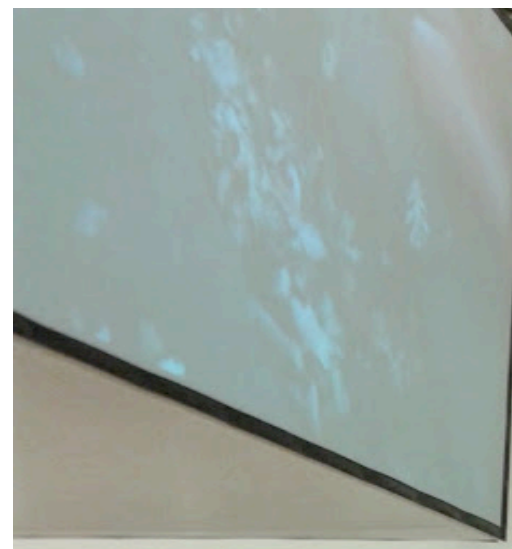

\section{r}

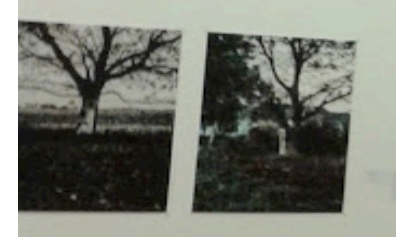

亡

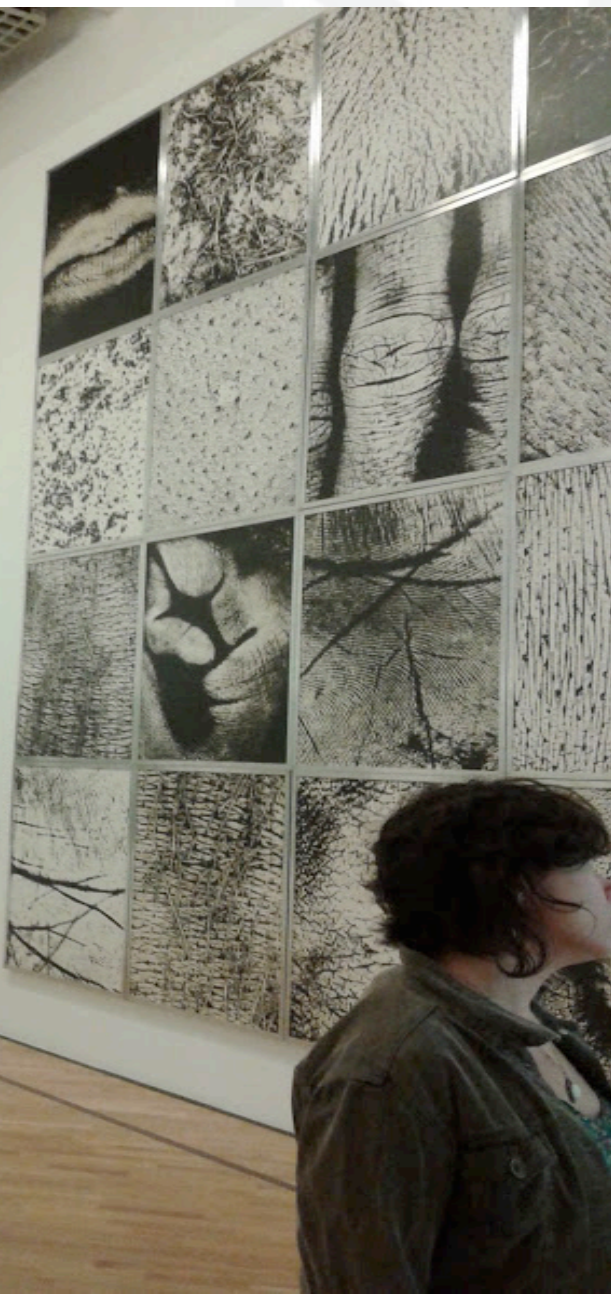

Fig. 6: Painel fotográfico Epidermic Scapes de Vera Chaves, sala da Pinacoteca. Fonte: Anna Maria Rahme

Corpo e paisagem se fundem tanto na mulher que se veste de barro e adentra o casulo cuja matéria prima é a terra em estado natural, quanto na construção do ovo geometrizado, uma metáfora repetida em duas caixas cúbicas revestidas por delicadas membranas brancas, uma de grandes dimensões em exposição e outra com aproximadamente $1 \mathrm{~m}$ de aresta. Em ambas as performances há um rompimento das cascas provocado pelos movimentos das artistas, em cada um dos cenários, o próprio ateliê ou à beira mar sobre areia.

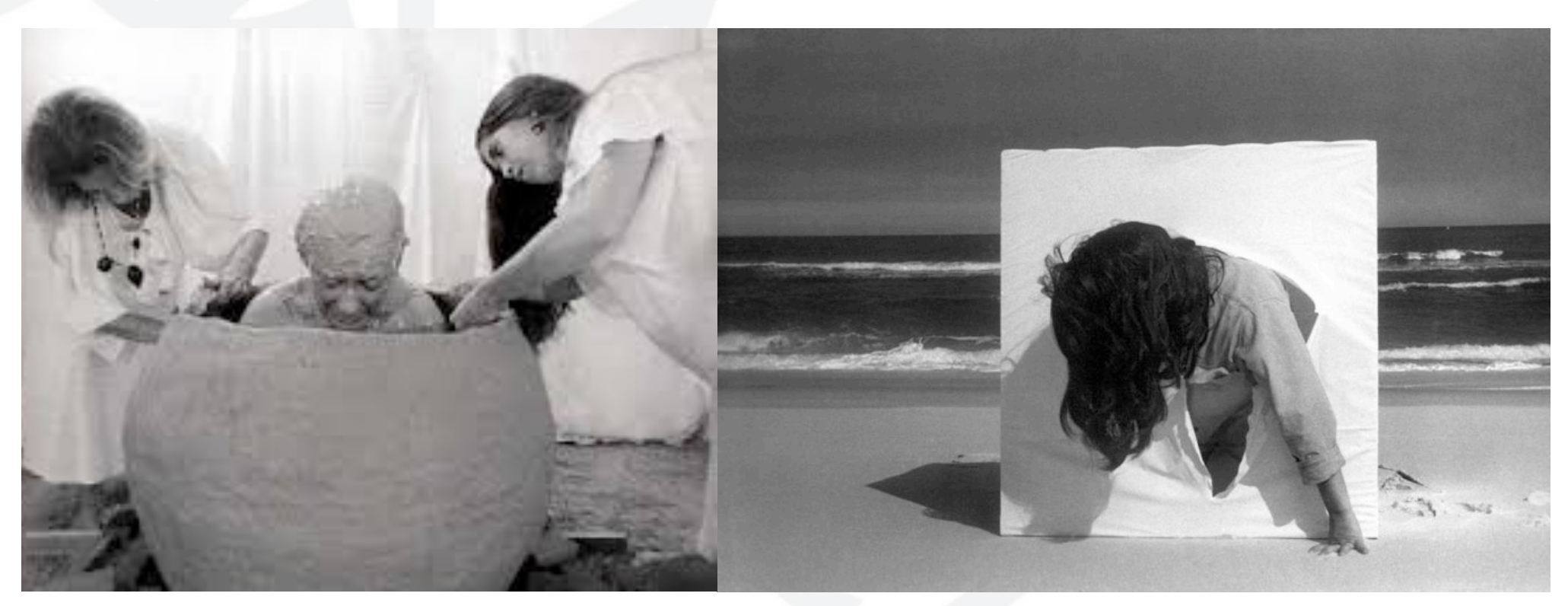

Fig. 7 e 8: Imagens do vídeo Passagem de Celeide Tostes O ovo de Lygia Pape. Fonte: Fotografia publicada no site da Pinacoteca, para divulgação do evento.

A área é compartilhada com uma outra membrana, de pele humana, são fotos que registram as nuances e formas imperceptíveis da superfície que nos reveste, revelando inúmeros caminhos, texturas e quase um outro universo de linhas e tons, aferindo densidade e a complexidade aos contornos e sombras. Os registros fotográficos estão reunidos num painel de amplas dimensões, Epidermic Scapes de Vera Chaves Barcelos. Cada zoom sobre o corpo feminino é uma paisagem contida em formas quadradas, se organizam em um único plano modular e, portanto, tem a possibilidade de expandir-se infinitamente, multiplicando o número de pontos focalizados. Esta representação sugere, como as anteriores, a ideia da quebra de barreiras e, pelo uso do corpo feminino, remete à luta por novos espaços e significados.

Ao constatar o ineditismo de muitas das obras na exposição Mulheres radicais, embora datadas de décadas atrás, surge a pergunta sobre o por quê da não inclusão de muitos dos fazeres artísticos na história da arte e sua historiografia. Recorde-se, então, que por um longo período a voz feminina foi calada seja 
pelos aspectos de denúncia de um sistema político autoritário e repressor, de um sistema social opressor ou por não interessar abrir às mulheres as portas dos lugares sociais de produção de conhecimento. Estes fatos conduzem à referência de Roger Chartier para a história, como disciplina científica, ser "suscetível de um enfoque similar que não dissolva o conhecimento na historicidade, [...] mas que reconheça as variações dos procedimentos e as restrições que regem as operações históricas" (2010, p.20).

Ações recentes de revisão e reconstrução de trajetórias pessoais, pouco conhecidas, permitem analisar o conjunto e reagrupá-los em leituras e interpretações múltiplas sobre aspectos como: a emancipação feminina, o medo, o erotismo, o corpo e a fertilidade pouco tratados ou pouco representados pelas próprias mulheres. A Pinacoteca do Estado que concentra um acervo composto em sua maioria por peças do século XIX e começo do XX, exibe um exemplo no pátio central e visível dos balcões que circunscrevem a exposição em análise.

Trata-se da obra Musa Impassivel (1920), homenagem póstuma de Victor Brecheret à poetisa parnasiana Francisca Júlia, uma alegoria à poesia plasmada numa altiva imagem feminina em estado de avançada gestação, gravando tridimensionalmente no mármore branco emoções e fecundidade, papeis associados à mulher e ainda perpetuados na sociedade brasileira do começo do século XX. A escultura representa a idealização masculina da mulher, caracterizada pela beleza clássica e a procriação, e negando a importância de suas emoções e produção de conheciment

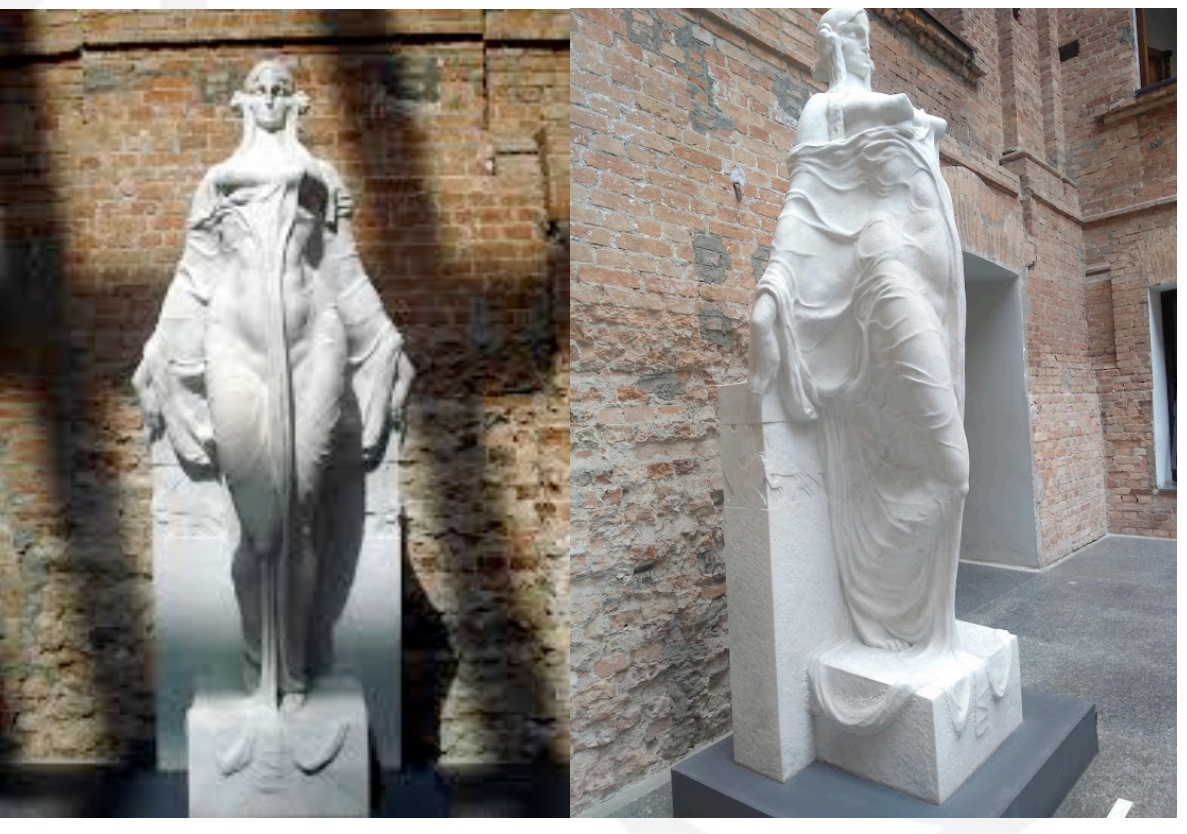

Figura 9: Musa impassível, 1920, Victor Brecheret. Fonte: Anna Maria Rahme.

A transcrição de entrevistas, a divulgação dos vídeos das palestras e as legendas que permeiam o espaço expositivo relatam invocações das curadoras que "[...] embora boa parte dessas artistas tenham sido figuras decisivas para a expansão e diversificação da expressão artística" na América Latina, ainda assim não haviam recebido o devido reconhecimento. Também, enumeram viagens, entrevistas, análise de publicações em apoio à intensa pesquisa, desde 2010, e acrescentam a intenção de "[...] consolidar, internacionalmente, esse patrimônio estético criado por mulheres que partiram do próprio corpo para aludir - de maneira indireta, encoberta ou explícita - as distintas dimensões da existência feminina".

\section{PRotagonismo FEMININO}

Os dizeres das curadoras confirmam a constatação de que a luta das mulheres extrapola e muito uma única sala - Feminismos - de um único museu, na vibrante capital paulista. Inaugura, sim, um forte movimento artístico composto por "mulheres radicais", contribui para abrir novos caminhos investigativos e entendimentos acerca de uma dada história latino-americana. 
E, mais ainda, que a garra dessas mulheres e suas posturas políticas se constituam em algumas, mas não a única força de resistência. São ações individuais e coletivas imbricando-se para configurar imagens e narrar microhistórias nas relações de contraste e complementaridade inseparáveis para a composição de uma mutável macro-história.

As manifestações de mulheres que saíram às ruas, no Brasil atual, para denunciar o preconceito, o racismo e as desigualdades de gênero, em pleno cenário pré-eleição de ameaças às conquistas democráticas, somam-se ao conjunto de peças expostas e conferem apreço, reconhecimento e atualidade ainda maior à luta feminina, que se anunciou nos anos 60 e permanece presente e necessária. A retórica do conjunto se amplia com as camadas de significados carregados de vibrações e debates contemporâneos que permeiam as recentes disputas políticas e sociais.

Um novo universo de mudanças sensíveis atingiu as práticas relacionadas ao corpo feminino - o corpo objeto se torna sujeito, a atitude de submissão em protagonismo - na construção da própria história, com novas atrizes, novos temas e novos signos. Antes figuras inertes à mercê da interpretação masculina, as mulheres elegem e expõem partes dos seus corpos despidos ou parcial ou completamente encobertos - e objetos eróticos - roupas íntimas destroçadas, máquinas de repressão ou tortura física. Essas artistas rebeldes nos recintos $O$ Poder das palavras, Mapeando o corpo e Erótico da mostra exibem a radicalidade dos atos que as vitimam, mas também os que ocultam sua existência e fazeres e que, naturalmente, não fazem parte do repertório masculino na representação da mulher.

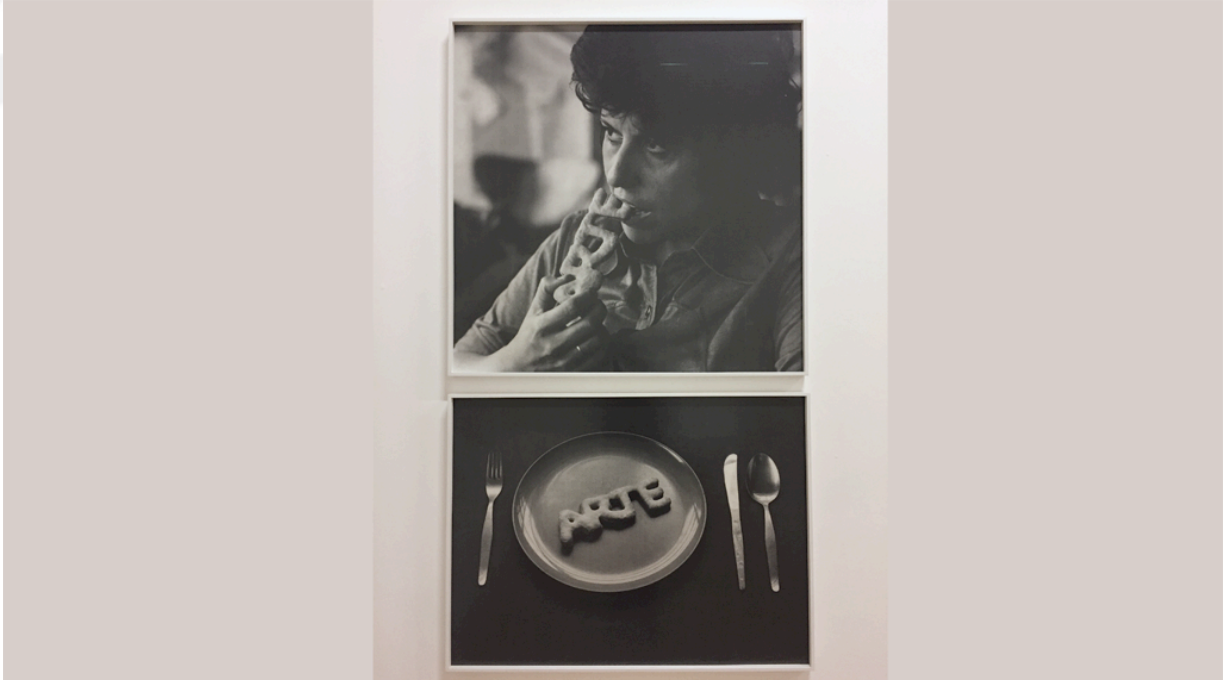

Fig. 10 Biscoito Arte, de Regina Silveira. Fonte: Fotografia feita pelas autoras na exposição da Pinacoteca do Estado de São Paul, out. 2018.

Uma delas, Regina Silveira, registra sua participação com recorte da palavra ARTE descontextualizada ou imagens do próprio corpo, por meio de videoperformances ou desenhos. Enquanto, Elena Gonzales, traz as Vulvosas em delicados desenhos tingidos de rosa, uma cor que subtrai parte da crueza do recorte e da aproximação focal desta parte inexpugnável para muitas, porque cercada de tabus preconceituosos. Alguns diriam que não há novidade alguma no tema, apresentado realisticamente por Gustave Courbet em $A$ Origem do Mundo ${ }^{12}, 1866$, antepondo-se à idealização do corpo feminino, vigente no século XIX. A diferença de significados, no entanto se revela na autoria, entre a visão de si mesma e o olhar do outro, explode no contraste entre identidade e alteridade.

Analisar as representações sob este prisma ressalta a importância do caráter feminino presente em Vulvosas, pela consciência de pertencimento que garantem a estabilidade e continuidade de uma dada cultura, segundo Chartier. Porque, enquanto a identidade como o reconhecimento do igual,

${ }^{12} A$ obra em óleo sobre tela, cujo nome original é $L$ 'Origine de monde, encontra-se no Museu D’Orsay desde 1995 
aproxima pelas semelhanças indivíduos e grupos que "[...] se percebem percebem os demais", a alteridade é a condição do outro e traduz a diferença das naturezas. Consequentemente, transmitem "[...] as diferentes modalidades de exibição da identidade social ou política tal como as fazem ver e crer os signos, as condutas e os ritos" (1989).

O fato, da exposição trazer a público os gestos de um estrato social significativo da sociedade latina, as mulheres, é mais uma valorosa manifestação contemporânea a favor da igualdade de direitos. Já que, estas práticas são estratégias simbólicas que levam ao reconhecimento de "uma identidade social, a exibir uma maneira própria de ser no mundo, a significar simbolicamente um estatuto e uma posição; enfim, as formas institucionalizadas e objetivadas" marcando de modo visível e perpétuo a existência do grupo.

Outras obras exibidas cumprem papéis semelhantes e adicionam repertório às estratégias, como é o caso do Hábito/Habitante, 1985, participação de Martha Araújo com fotografia, que mostra a autora em pose contida pela própria estrutura rígida da vestimenta fixada na parede e tolhendo-lhe os movimentos. $O$ corpo quase que totalmente encoberto é engessado 'nas suas impossibilidades', rompidas apenas por inexpressivas partes - cabeça e mãos a romper o desenho da túnica negra, o 'habito'. Alusão ao movimento de resistência contra a restrição à liberdade de expressão, igualmente presente em duas fotoperformances: Poema, 1979, de Leonora de Barros e Sem Título, 1983, de Liliana Maresca.

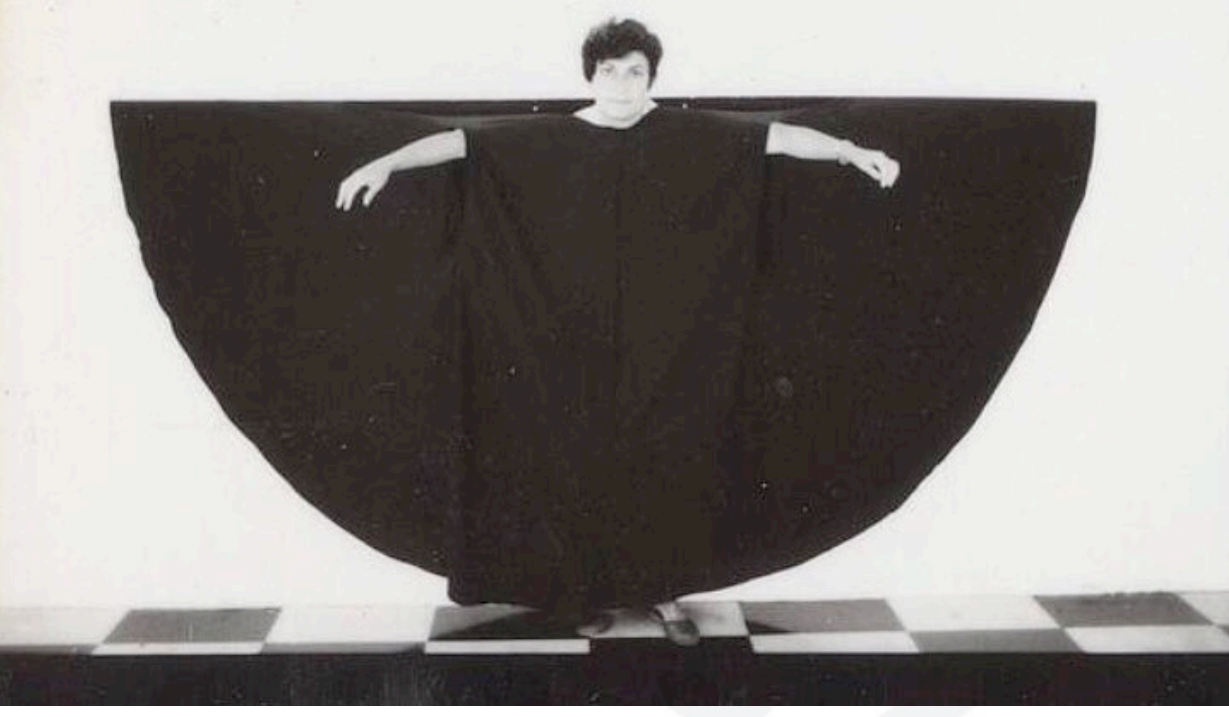

Fig. 11. Martha Araújo, Hábito/Habitante (Habit/inhabitant), 1985. Fonte: Registro da performance, fotografia em preto e branco. Coleção da artista. Cortesia da Galeria Jaqueline Martins, São Paulo, para divulgação da exposição.

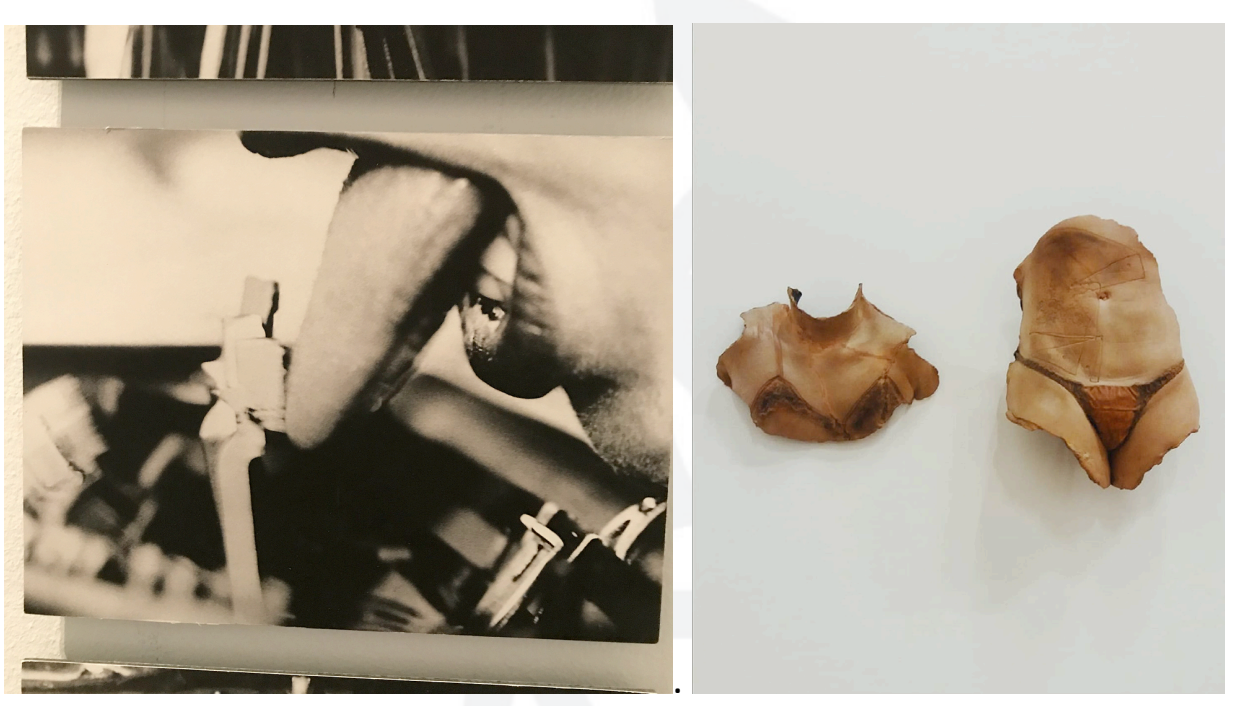

Figura 12, 13: Poema, 1979, de Lenora de Barros (à esquerda). Sem Título, 1983, de Liliana Maresca. Fonte: Fotografia das autoras na exposição Pinacoteca, out. 2018.

Dois trabalhos que refletem o cerceamento da mulher nos recentes anos de exceção pela dor da tortura imposta por máquinas, a um só tempo, emoldurando as carnes e as estrangulando. Apesar da aparente sujeição aos 
instrumentos, as imagens revelam escravização aos modelos impostos, porque amarras tolhem os movimentos e marcam indelevelmente o ser, com restrições que se estendem da palavra falada e escrita, à libido, trancada em proibições. Uma mesma libido destruída, um poder de sedução destroçado, também constatado na peça de Nelly Gutmacher, Arqueologia do desejo, 1982, na proposta intimidade que se desvenda por uma remota beleza partida.

\section{CONSIDERAÇÕES}

Da mesma maneira que o esquecimento a condição da memória, o apagamento é a do escrito. Roger Chartier (2010, p.20)

Embora abarque a produção artística dentro de um período circunscrito, a exposição Mulheres radicais: arte latino-americana 1960-1985 trabalha as obras construindo mensagens não literais dos tempos de repressão na América Latina do século $\mathrm{XX}$, falam de tempo e representação, dois conceitos que contribuem para iluminar a atualidade da mostra, inserindo-as nas turbulentas manifestações em espaços públicos brasileiros. Apesar de não recorrer ao apelo fácil da espetaculização, trazendo o aspecto chocante das ações ditatoriais, ou mesmo edulcorando passagens para tornar o evento mais palatável, a curadoria da mostra apresenta uma imensa gama de peças cujos conteúdos extrapolam os fatos históricos ocorridos nos vinte cinco anos anunciados. Mesclando temas e técnicas cada uma das peças presentes resignifica os acontecimentos pela rememoração, deixando a esperança de que não se repitam jamais. Deste modo, conduzem ao entendimento que a proposta do evento não se reduz ao recorte cronológico do título, mas provoca a memória, ressuscita esperanças e constrói possibilidades.

Portanto, a escolha das conceituações de Roger Chartier se adéqua ao entendimento da obra de arte não como simples imagens do real, verídicas ou enganosas, mas pela energia que thes é própria e as capacitam mais do que reproduzir uma sociedade, a produzi-la. Porque as representações definem em cada momento da experiência social, limites, fronteiras, classificações, identificações, contribuindo com a estruturação de uma dada realidade social e não nos afastando dela. O esforço de reunir tal material e exibi-lo pode ser comparado a atos femininos de coragem e audácia como foram e são as manifestações de rua pelas igualdades, independentemente do gênero.

Tais fazeres, agora trazidos a público e os modos pelos quais nos foram apresentados transformam a ação comunicacional em educativa, pela transferência de valores, conceitos e saberes dessas práticas, como prega o Conselho Internacional de Museus/ICOM, antevendo a autonomia das pessoas no processo de mudanças e transformações, além da difusão de conhecimento. Por outro lado, agrupa conteúdos e os classifica, por similaridades e distinções, promovendo leituras variadas para as propostas e o reconhecimento que leva à aproximação ou rejeição. Tem-se então a identidade ou a alteridade como afirmação, respectivamente, do igual e do diferente.

Esta consciência identitária surge em Autorretrato quase como uma autobiografia para configurar imagens e narrar micro-histórias nas quais cada artista lança o olhar sobre si mesma e se expõe da maneira que deseja ser vista. Esta mesma busca de caráter individual se revela na relação com a natureza em Paisagem do corpo, sub-tema no qual a integração com elementos primordiais - barro, areia, vegetação - remetem à mãe-terra Gaia, deusa da mitologia grega, e seu caráter gerador. Um poder, também gerador de outras naturezas cruas ou poéticas, instaurando rupturas e/ou beleza, estranhamentos e adequações.

Já, a Performance do corpo introduz movimentos individuais ou em grupo, propondo sincronicidades que os identificam e promovem relações de contraste e complementaridade inseparáveis para a composição de uma mutável macro-história. A força desses movimentos reside exatamente na relação de troca, somando participação e integração às atitudes individuais e coletivas. Na seção Mapeando o corpo aparecem representações com questões singulares de inadequação e estranhamento com a imagem à qual 
cada personagem é associada, nascendo então apropriações de gênero e formas incompatíveis com a própria figura.

Os cerceamentos às liberdades de escolha são as sementes dos projetos de enfrentamento em Resistência e medo. Um momento trágico na história das democracias latino-americanas, quando o medo trouxe o emudecimento, mas o inconformismo fez germinar movimentos de radicalização. Radicalização política que tingiu de rupturas as artes nacionais, introduzindo novos modos de comunicação entre autor e público, trocando a observação passiva pela ativa, rompendo molduras e estaticidades, usando recursos dinâmicos e cinéticos e luminosos.

Tais estratégias substituíram os discursos da voz interrompida e $O$ poder das palavras não veio pela escrita, altamente censurada, mas por monossílabos inseridos em imagens do cotidiano, em simbiose com objetos inusitados, em gritos visuais. Gritos expressos na luta pela igualdade de direitos sociais, do sufrágio à equiparação salarial e pessoal, de bens e serviços à liberdade de expressão. Engajadas em grupos identitários essas mulheres fundaram o Movimento Feminista, cuja militância vem se modificando seja pela própria organização, seja pelas demandas. A curadoria da mostra preferiu chamar de Feminismos, os diferentes modos de atuação pela afirmação do gênero.

Um feminismo que atravessa barreiras e se faz, igualmente, presente nos Lugares sociais com registros das manifestações de protesto contra as diferenças impostas no mundo ocidental, especialmente o latino-americano, por mudanças que representem conquistas individuais e coletivas. Neste setor da exposição é possível detectar os registros feitos em bordeis e comunidades trans, bem como da atuação individual pela defesa da dignidade humana e o direito à própria expressividade. Aqueles discursos de curta duração nos informam sobre sociedades patriarcais e opressivas, contra as quais a luta teve que se acirrar, para afirmar posições e conquistar lugares na comunidade, em especial o lugar do feminino.
O grande desafio foi batalhar contra os estereótipos sobre o papel da mulher nestas sociedades, sem dúvida uma árdua questão se considerarmos a arma que estava em jogo, a sedução. Como angariar adeptos aos novos ideais? Nas primeiras décadas de existência, a oposição ao movimento teve farto materia para denegri-lo graças ao radicalismo das estratégias das organizações, rotulando suas adeptas de 'mulheres mal amadas' entre outros. Porém, a tática utilizada pelas feministas surtiu o efeito desejado e os primeiros tempos de luta, enfrentados com garra e persistência, resultaram em avanços e afirmações pessoais e sociais.

As práticas utilizadas exerceram, portanto, alteração do foco da sedução, do corpo para as ideias. Há que fazer disto uma bandeira e a arte aceita ta desafio, quando utiliza os mesmos instrumentos de desejo e de prazer a favor de seus projetos. Segundo a curadoria da mostra, à poética do setor Erótico deve-se a exibição proposital no final do percurso, talvez na busca de diminuir o impacto daquelas peças de conteúdos mais sinistros. Poéticas ou não, estas representações constroem o universo desejado, criativo e crítico, pensando e materializando formas de destruição de tabus e preconceitos, oferecem perspectivas de que sua circulação, como profetizou Roger Chartier, faça sentido em um tempo e lugar concreto.

\section{BIBLIOGRAFIA}

Chartier, Roger. A história cultural: entre práticas e representações. Lisboa: Difel; 1990.

Chartier, Roger. A história ou a leitura do tempo. Belo Horizonte: Autêntica Editora; 2010.

mundo como representação. Annales. № 6, nov-dez. 1989, p. $1505-1520$

Entrevista: Do mundo como representação à multiplicidade das formas de representação do passado. Historia e historiografia. Ouro Preto, n. 22, dez. 2016, p. 296-319, doi: 10.15848/hh.v0i22.1185. 
Desvallées, André e Mairesse, François. Conceitos-chave de museologia. São Paulo: Comitê do Conselho Internacional de Museus; Pinacoteca do Estado de São Paulo; Secretaria do Estado e da Cultura; 2013.

Jauss, Hans Robert. A história da literatura como provocação à crítica literária. São Paulo: Ática; 1994.

\section{Fontes eletrônicas e sites}

https://pinacoteca.org.br/programacao/mulheres-radicais-arte-latinoamericana-1960-1985/

https://www.nexojornal.com.br/expresso/2018/08/20/As-5-obras-exclusivasda-exposi\%C3\%A7\%C3\%A3o-\%E2\%80\%98MulheresRadicais\%E2\%80\%99-no-Brasil

https://www.bbc.com/portuguese/brasil-45700013

https://folha.com/sxhe76ma

https://www.youtube.com/watch?v=Cka9v-Go6KU

https://www.youtube.com/watch?v=49-wQtOj7il

http://www.verachaves.com/biografia.html

https://deskgram.net/explore/tags/radicalwomenlatinamericanart

http://nellygutmacher.com.br/nelly-gutmacher-lista-de-obras/

https://www.youtube.com/watch?v=Owmzmz1DKIU\&feature=youtu.be 